\title{
A CASE STUDY OF MMO,'S MADIC: A FRAMEWORK FOR CREATING MOBILE INTERNET SYSTEMS.
}

Keywords: $\quad$ Mobile Applications, Wireless Reference Model, MADIC, Mobile Internet,

Abstract: Mobile Internet applications on ubiquitous mobile networks allows real-time, anywhere, anytime connectivity to services. Due to its scalability and potential cost savings, mobile communication is being increasingly applied in the business and consumer communities to create innovative data and voice application, which run over the Internet infrastructure. This paper reports on a case study at an organisation that created an innovative approach to developing mobile applications developed by third party independent developers. A conceptual wireless reference model is presented that was used to define the various system components required to create effective mobile applications. 


\section{INTRODUCTION}

Technological changes in telecommunications have led to a major transformation in the sector. Technological advancements has led to the integration of traditionally separated services like voice and data services. Mobile phones have become an integral part of our everyday lives. The mobile phone has changed from being a product marketed almost exclusively for business people to a mass consumer item with over $75 \%$ of the UK population owning a mobile phone (Oftel 2003). This transformation of mobile phones into a mass consumer product and an integral part of business life in the UK has been delivered through competition. Competition has been the spur for companies to drive down prices, widen their customer base and provide new services. The ability of Third Generation Networks (3G, UMTS) to carry video and sound clips is seen as a large potential revenue stream for Mobile Network Operators (MNO). However, currently MNOs are finding it difficult to justify the levels of investment. Mobile data services are not mentioned as a revenue source in Oftel reports (Oftel 2003) as only negligible revenue is generated by this means. With the current challenges faced by MNO, drastic changes are needed over the next five years to combat huge debts, low share values and dwindling market shares. Most of the MNOs realise that the mobile data service offerings are inadequate and the mobile data market is currently an unknown and untapped potential. MNOs and other technological organisations such as handset manufacturers are devising new approaches to work with different organisations of various sizes and capabilities to form joint partnerships to develop Mobile data capabilities. One such approach is the development of innovative organisations to fuel the development of data products.

This paper reports on an exploratory case study at an organisation involved in the development and integration of mobile applications. The study investigates an innovative approach to developing and deploying mobile applications produced by independent third parties. The first section describes the research method used for the study. This is followed by an introduction into the current trends of developing mobile technologies using a project based delivery approach. The next section describes the concept of 
mobile portals and discusses an example from the case study. The background to the case study is presented illustrating the infrastructure, technology and people. A discussion on the mobile Internet follows with an explanation on how the mobile applications registered at the case study are addressing the mobile Internet limitations. Prior to the conclusion, the paper presents the end-to-end process for delivering the mobile applications and introduces a conceptual framework for understanding various system components required to create effective mobile applications. The framework defines central elements and proposes a common vocabulary of terms for describing the wireless constituents.

\section{Research Method}

The research method that was adopted in order to investigate MADIC was a case study approach. The case study was exploratory in nature and its sole purpose was to generate knowledge on the methods, techniques and technologies in use at MADIC to launch mobile applications. Yin (1994) defines the scope of

a case study as follows: "A case study is an empirical inquiry that: investigates a contemporary phenomenon within its real-life context, especially when the boundaries between phenomenon and context are not clearly evident". The purpose of conducting the case study was to obtain knowledge about the methods, techniques and technologies used by MADIC to launch mobile applications. Two types of data collection methods were used during this study: in-depth open-ended interviews; and written documents. The data from the interviews consisted of taped records and interview notes, which were later transcribed. The recorded elements included direct quotations from people about their experiences, opinions, feelings, and knowledge.

\section{CURRENT TRENDS FOR MOBILE TECHNOLOGY DELIVERY}

Studies of innovation have pointed to the use of a new form of organisation to cope with the increasing complexity of production, communications and technology (Miles, Snow et al. 1997) (Hughes 1998) (Rycroft and Kash 1999). These suggest that firms have become increasingly reliant upon projects to organise the 
development of complex products and systems (Gann and Salter 2000). This has led to a new trend in many organisations toward a project-based approach to organisational design (Miles, Snow et al. 1997) (Hughes 1998). Howard et al., (1999) argue that this trend also decentralises system-building activities due to system components running on many separate servers and system developers being geographically dispersed. The trends in mobile technologies also reflect sharing amongst organisations for mutual benefits (Olla and Patel 2002). For example, the wireless network infrastructure may be provided by one organisation whilst another organisation may provide the applications software and hardware platforms. Increasingly, organisations make use of a shared infrastructure and applications provided for them by specialist third party organisations. These third party organisations may consist of technology companies, business service providers, or even a consortium of several organisations from various industries. This means that mobile applications are increasingly being developed as discrete components, represented as packages, platforms or as 'ready-to-attach' modules. These mobile applications are hosted on the internet and are accessed via mobile mortals. Mobile Portals build on the Internet's existing communications and commerce strengths to intelligently deliver content to a variety of portable end-user devices such as mobile phones and Personal Digital Assistants (PDA). The portal may generate the content itself or use content from alternate third party content providers.

\section{Mobile Portals}

Sabat (2002) describes an internet portal as a network site that aggregates, presents, navigates, and delivers a wide range of internet communication, commerce, and content services to a large number of visitors. Popular portals, such as Yahoo or AOL, are distinguished from traditional internet sites because they are designed to serve a large number of users or visitors (millions per day) with a significant amount of usage (page views). Portals employ various 'usage-driver' services. For example, they provide value-added services to keep visitors on the site longer and lure them to return more frequently. Thus, 'usage-driver ' features convert the 'click-through' traffic volumes generated by many search engines into 'stay-and-play' 
visitors. Value-added services might include free news, e-mail, chat, personalised content, financial services, on-line shopping areas, and community and Internet access.

However, the content needs to be reformatted for the wireless world. Key players in the provision of services to subscribers are Mobile Service Providers (MSP) and Mobile Network Operators (MNO). Mobile service providers provide access to Internet services and their role also involves the reselling of mobile airtime. An example of a mobile portal obtained from the case study was a site called 23 rdFloor.com (23F). $23 \mathrm{~F}$ is a site aimed at the 16-24 year old mobile phone user and offers everything from music and downloadable images, to interactive mobile entertainment. $23 \mathrm{~F}$ is a collaboration between three parties Airside, the Mobile Applications Development and Integration Centre (MADIC) and independent developers. MADIC is an $\mathrm{MMO}_{2}$ initiative to help application developers create successful products, and get them to market as quickly as possible, this represents a new form of value chain (Barnes 2002). The objective of the site is to create a test platform for independent developers working specifically on mobile entertainment services for the 'youth' market. Airside is a creative design agency founded in 1997 that develops digital media content specialising in Internet and music with a track record in high-profile web design work for MTV. The site illustrated in Figure I is designed to be a market test platform or 'nursery' to evaluate the third party products. After a period of time products will be assessed in terms of how much they have been used by $23 \mathrm{~F}$ customers on the website. The most successful services could potentially be deployed via other $\mathrm{MMO}_{2}$ channels. Independent developers register their products via the MADIC website for evaluation similar to other products for evaluation. Since MADIC is the main focus of this study a more detailed overview is provided in the following section. 


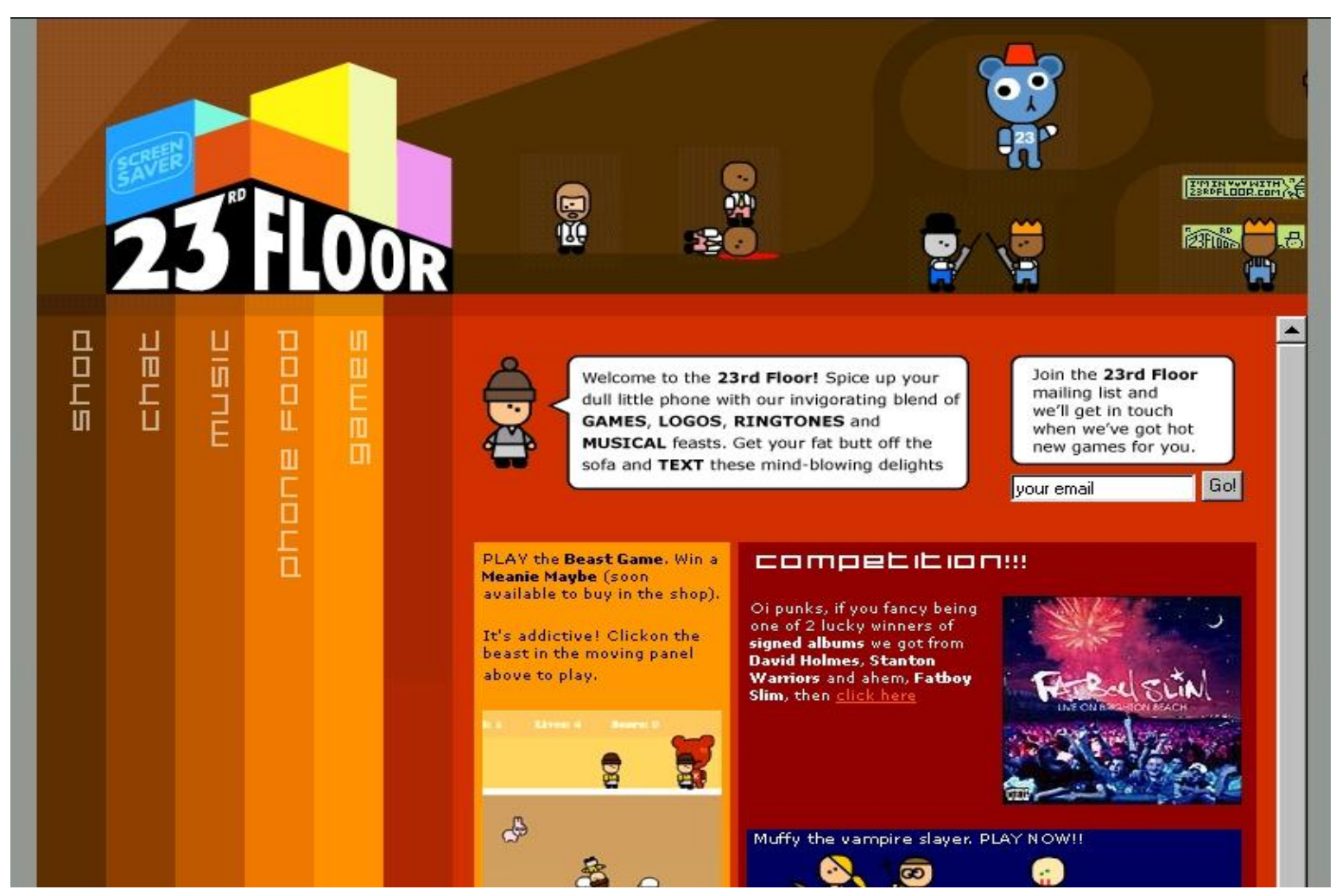

Figure I: 23F Home Page

\section{BACKGROUND TO MADIC}

MADIC was initiated to act as a 'Creative Innovation Centre' for third party developers to expedite their ideas to wireless data networks by a collaboration between BTwireless and BTCellnet in May 2000. These organisations were de-merged from $\mathrm{BT}$ in 2001 and have been re-branded as $\mathrm{MMO}_{2}$. MADIC's objective is to strike up partnerships with third party application developers and to speed up time to market for profitable products. MADIC operates by creating strong links with the third party development community. A forum is hosted at regular intervals called the Application Developer Forum (ADF) where prospective partners are briefed on the benefits of developing products with MADIC. A website is also available to the third parties and is the primary means by which MADIC realises new opportunities. Third party developers register on the MADIC website in order to promote themselves and their products to $\mathrm{MMO}_{2}$. 


\section{Client Infrastructure}

To exploit the complex markets emerging in the wireless telecommunication market, MADIC was set-up with three 'Principle Ingredients': Positioning, People and Technology, which are explained respectively.

Positioning: MADIC occupies a 'middle ground' location between the areas of media, the web and wireless environment as depicted in Figure II The mobile applications registered by third party developers are from various sectors as depicted in Table I:

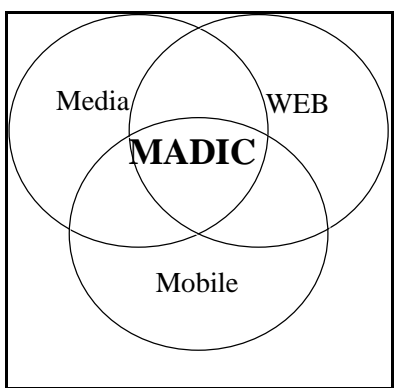

Figure II MADIC Middle Ground Position

\begin{tabular}{|l|l|}
\hline Markets Mobile applications aimed at. & Numbers \\
\hline Telecommunications & 146 \\
\hline Consumer & 236 \\
\hline Corporate & 321 \\
\hline Government & 18 \\
\hline Other & 57 \\
\hline SME & 75 \\
\hline SOHO & 6 \\
\hline Vertical markets & 120 \\
\hline Grand Total & 979 \\
\hline
\end{tabular}

Table I: Target Market for Mobile Applications

People: MADIC comprises of a multi-disciplinary team capable of replicating the $\mathrm{MMO}_{2}$ business functions. These are made up of the typical wireless operator centric staff comprising of Information Technology, 
Network Technology, Marketing, Regulatory, Legal and Commercial. MADIC comprises of three different types of people:

a) Samurai: They are referred to as the 'deal makers' and are the intermediary between the third party developer and the delivery function for MADIC. The Samurai role is equivalent to a Business Development Manager;

b) Noah's Ark: This team is made up of the typical wireless operator centric staff comprising of Information Technology, Network Technology, Marketing, Regulatory, Legal and Commercial. The term Noah's Ark signifies the fact that every business function is represented;

c) Operations Staff: They are the core team to run the operations and administrative functions of the centre.

Technology: The technical wireless infrastructure includes testing environments to allow third party developers to test their applications and services working over the wireless infrastructure. Experience with the introduction of new services over the wireless data network have shown that Internet Protocol (IP) based applications that work perfectly well over wired networks may not perform reliably over a wireless data network (Kindberg and Barton 2001). Since most of the products that are registered with MADIC are 'ready to market' (see Table II) providing this service is intended to aid third party developers and reduce time to market.

\begin{tabular}{|l|l|}
\hline Development Stage & Total \\
\hline Concept & 33 \\
\hline Design & 39 \\
\hline Development & 103 \\
\hline Feasibility & 16 \\
\hline Ready for launch & 606 \\
\hline Testing & 182 \\
\hline Grand Total & 979 \\
\hline
\end{tabular}

Table II: Development Stage of Mobile Applications Registered 
The products are usually not purchased outright, instead developers are compensated on a revenue share basis from revenues generated by the product or service. The reason for this approach is to mitigate risk. The applications' developer has access to various levels of funding. If required, funding can be arranged by MADIC when the application is innovative or the company have financial difficulties. Products selected for assessment are usually data applications nearing the end of their development cycle or ready for market. The mobile applications registered provide a view of the type of technologies that will be influencing the future of the Mobile Internet, they are being developed with the limitations of the current mobile internet in mind.

\section{EVOLUTION OF THE MOBILE INTERNET}

This section describes the technology that constitutes the European version of the Mobile Internet and Table

III presents the main reasons for the disappointing take-up and how the new set of applications addresses these issues. It would be negligent to discuss the Mobile Internet without discussing the i-mode service, as it is the most successful Mobile Internet service. Launched in early 1999, NTT DoCoMo's i-Mode service is the world's largest wireless Internet service, with more than 43 million subscribers at the beginning of 2003 (Docomoco 2003). This makes it one of the largest fee-paying ISPs in the world. (Anderson January 2002). The European networks launched their service based on Wireless Application Protocol technology (WAP) in 1999 (Anderson January 2002) and this was described and promoted as the 'Mobile Internet'. A combination of the vendor hype, false and over-enthusiastic press coverage led to a disappointing take-up and user experiences of the initial WAP launch in 1999 (MacKenzie April 2000; Anderson January 2002). The users had expectations that WAP will provide capabilities and characteristics that were not available and may never be via the WAP medium. There was an expectation the Mobile Internet via WAP phones would emulate everything the PC can do whilst on the move. Although Mobile Internet portals became available there was moderate use of the service (MacKenzie April 2000), due to the limitations illustrated in Table III. 


\begin{tabular}{|c|c|c|}
\hline $\begin{array}{l}\text { Limitation of the Mobile } \\
\text { Internet }\end{array}$ & Description of Limitation & $\begin{array}{l}\text { How the registered Applications Address the } \\
\text { Issues }\end{array}$ \\
\hline $\begin{array}{l}\text { Unable to Surf using the } \\
\text { devices: }\end{array}$ & $\begin{array}{l}\text { Access was achieved through cascading } \\
\text { menus, which were not efficient, for the } \\
\text { tasks required }\end{array}$ & $\begin{array}{l}\text { The bulk of the applications work with } \\
\text { browsers based on WinCE/Pocket PC, Java } \\
2 \text { Platform, Micro Edition (J2ME) or Palm } \\
\text { Operating System (OS) software. }\end{array}$ \\
\hline Site Translation & $\begin{array}{l}\text { WAP was originally defined to translate } \\
\text { Hypertext Markup Language (HTML) into } \\
\text { Wireless Markup Language (WML). } \\
\text { However this never materialised and } \\
\text { content providers were obliged to WAP- } \\
\text { enable their websites }\end{array}$ & $\begin{array}{l}\text { Some of the registered applications reside } \\
\text { between the host website and the devise and } \\
\text { translate the information to a readable format } \\
\text { for the devise eliminating the need to } \\
\text { translate the websites and maintain duplicate } \\
\text { sites. }\end{array}$ \\
\hline Internet Access Speed & $\begin{array}{l}\text { The Global System for Mobile GSM } \\
\text { network on which WAP was initially } \\
\text { launched is not optimal for WAP because } \\
\text { it required long connection times and was } \\
\text { based on time-based charging. This } \\
\text { made WAP a time-consuming and an } \\
\text { expensive experience }\end{array}$ & $\begin{array}{l}\text { The new set of applications being designed } \\
\text { for the PDAs and laptops are based on the } \\
\text { General Packet Radio Services (GPRS), that } \\
\text { provides data rates from } 56 \text { up to } 114 \\
\text { Kilobytes per second (KBPS), and is always } \\
\text { connected. }\end{array}$ \\
\hline Push Technology & $\begin{array}{l}\text { Information push standards have been } \\
\text { defined in version WAP } 1.2 \text { they have not } \\
\text { implemented into WAP technology. }\end{array}$ & $\begin{array}{l}\text { The bulk of the applications for advertising } \\
\text { and content provision on technology that } \\
\text { allows information to be pushed to the } \\
\text { devices. }\end{array}$ \\
\hline Multi Media Content: & $\begin{array}{l}\text { There were limited multi media content } \\
\text { features }\end{array}$ & $\begin{array}{l}\text { There are now a variety of applications that } \\
\text { send rich content via the Mobile Internet. } \\
\text { They use a variety of compression } \\
\text { techniques for video and sound. }\end{array}$ \\
\hline $\begin{array}{l}\text { Location Based } \\
\text { Information }\end{array}$ & $\begin{array}{l}\text { One of the drawbacks of the initial WAP } \\
\text { launch was the inability to support the } \\
\text { use of location-based information for } \\
\text { mobile data services. }\end{array}$ & $\begin{array}{l}\text { This has been adequately addressed with the } \\
\text { network operators and service providers } \\
\text { offering the technology that can be } \\
\text { incorporated into mobile applications. }\end{array}$ \\
\hline Security & $\begin{array}{l}\text { Weak security concerns with the } \\
\text { encryption and decryption mechanism at } \\
\text { the WAP gateway. }\end{array}$ & $\begin{array}{l}\text { Although these issues have been addressed } \\
\text { in some of the applications, this is still a hot } \\
\text { topic in the IS research arena. (Spreitzer and } \\
\text { Theimer 1993). There are } 268 \text { applications } \\
\text { registered in this category that offer security } \\
\text { features at various level with transactions } \\
\text { protection for mobile communication }\end{array}$ \\
\hline
\end{tabular}

Table III: Limitation of The Mobile Internet

New applications are being developed that address these limitations. From reviewing the applications registered at MADIC and comprehending the network upgrades that are planned for the future, this paper is able to anticipate how the applications address these problems. One of the main criticisms of the WAP enabled Mobile Internet was the lack of innovative applications (Lee 1999). However, this does not appear 
to be the main problem considering the volumes of products available. Over 6,000 users are registered with the MADIC forum with 1211 registering products. The problem is not the capability of the technology or the infrastructure as previously thought (Olla and Patel 2002), but the ability to combine the respective technologies to create mobile services. As pointed out by MADIC's head of delivery, "The process for integrating all the various components is a complicated process which requires a lot of co-ordination especially when you incorporate the various external stakeholders".

\section{END TO END PROCESS FOR DELIVERING 23F APPLICATIONS}

The launch platform 23F evaluated 63 applications with applications including: online content; chatrooms; online games; ringtones generators; and logo generators. This platform is WAP capable and blurs the distinction between Internet, mobile and entertainment. It combines elements of each in live and virtual events, and is intended to become a cultural focus for the target youth market. The site hosts a Short Message Service (SMS) interface, with other Application Protocol Interfaces (API) under development, enabling rapid development and deployment of applications by third parties. These APIs, with appropriate technical advice are available to developers from the MADIC facility. Successful games and applications can be readily migrated into $\mathrm{MMO}_{2}$ channels. Some of the applications delivered via this route are listed

\begin{tabular}{|l|l|l|}
\hline Application Name & Description of Application & Developer \\
\hline MFighters & $\begin{array}{l}\text { A virtual SMS battle between users. Relies on } \\
\text { location-based API technology uses SMS }\end{array}$ & Emuse \\
\hline $\begin{array}{l}\text { Sports Games } \\
\begin{array}{l}\text { Penalty-Line }{ }^{\text {TM }} \text { (Football game) } \\
\text { Virtual Swing }\end{array}\end{array}$ & $\begin{array}{l}\text { Games based on sporting concepts which allow } \\
\text { players to test their ability to perform under pressure } \\
\text { in the world's most famous sports. }\end{array}$ & Springtoys \\
\hline $\begin{array}{l}\text { Prize Winning Games } \\
\text { Safecracker, Holidaze, } \\
\text { Treasure Hunt }\end{array}$ & $\begin{array}{l}\text { Answer general knowledge questions to open the } \\
\text { safe to see if you've won the prize. }\end{array}$ & CMM/ Espresso Life \\
\hline Txtm8s' & $\begin{array}{l}\text { mobile communities: chat; finder; reminder ; share; } \\
\text { vote; join; invite and evict. }\end{array}$ & Yakara \\
\hline
\end{tabular}

below with a brief explanation in Table IV.

Table IV : Examples of 23F Applications

This section describes the end to end process for delivering applications via the 23F platform illustrated in

Figure III. The process consists of four stages which incorporates the following: identify appropriate 
application from registered products; conduct technical and commercial feasibility; integration and implementation; soft launch application; monitor application against pre defined targets and criteria, full launch or withdraw application.

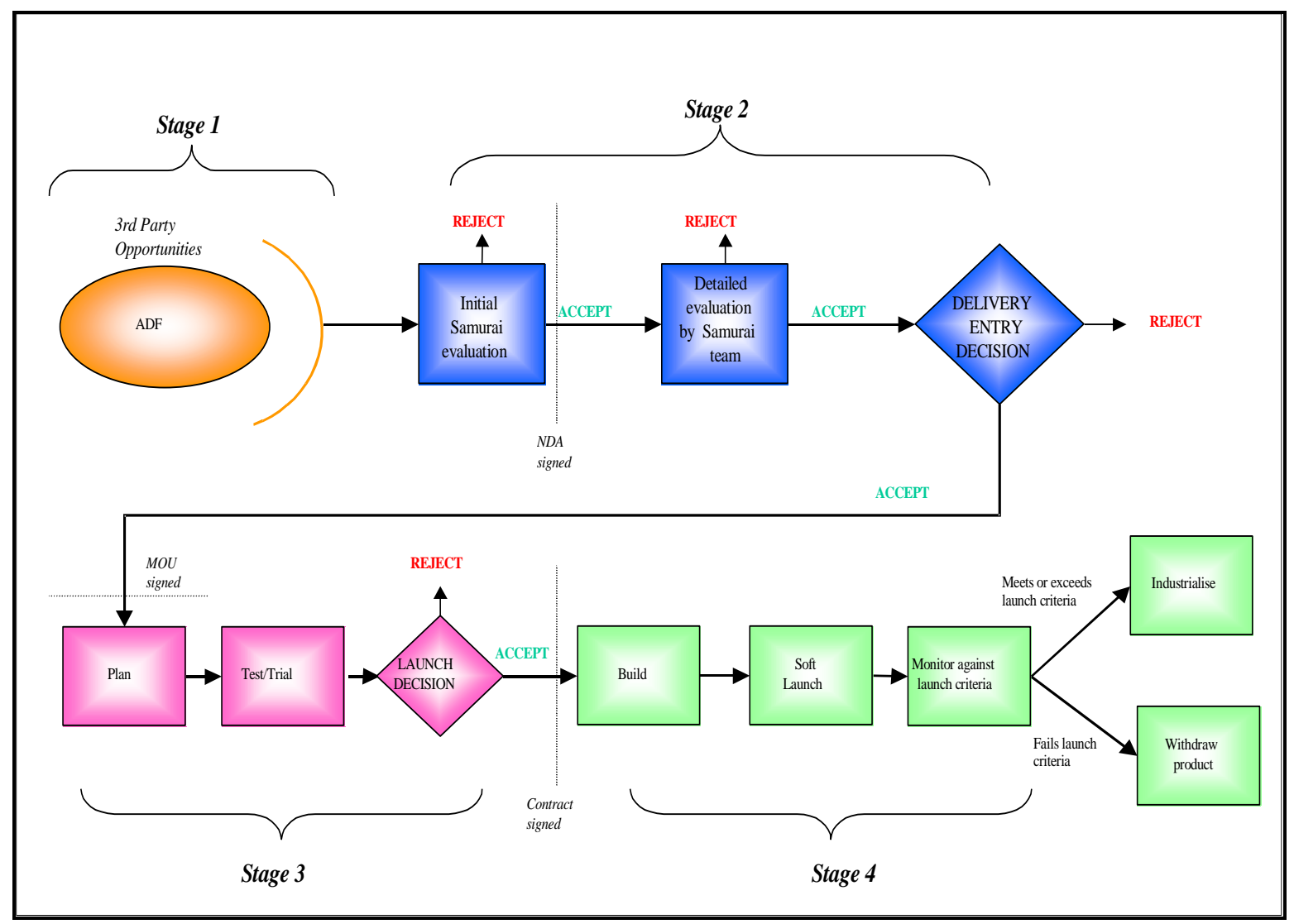

Figure III : End to End Delivery Process

Stage 1 Identify Opportunities:

The main source of applications are referrals from the ADF website, other sources include the web and word of mouth in the industry. The webmaster constantly scans for new creative and innovative opportunities.

Stage 2 Feasibility and Evaluation

The Samurai initiates first contact with the third party developer and ensures the product details are registered on the database. The next step is the completion of the confidentiality agreement process. The Non Disclosure Agreement (NDA) template is completed and the webmaster ensures that the developer 
signs the NDA. Should the developer require any changes to the NDA, the webmaster engages the legal team. The Samurai hands over the management to the webmaster to conduct an evaluation. The webmaster evaluates the application against the following criteria: brand; usability; target market; and profitability. If the mobile application passes these criteria, the webmaster passes the product over for technical assessment. The main objective of the technical assessment is to determine the implementation requirements such as: hosting; website integration; billing; and any other special requirements. Typical SMS applications can utilise the MADIC SMS game engine for speed and cost but can also connect directly to the $\mathrm{MMO}_{2}$ Short Message Service Centre (SMSC). Once the technical assessment is complete the contract negotiations with the developer commence. The Samurai operates by offering a revenue share deal with the developers as explained in an interview "We never offer to buy a product outright no matter how compelling or innovative the developer says they are, we only operate a revenue share scheme with our partners. We share the risks and the benefits". The Webmaster ensures that the contract is signed before the game is launched. If the technical assessment indicates that it will prove too costly or impractical to implement the application, the webmaster will inform the developer that his application has been unsuccessful.

Stage 3 Implementation

This stage involves the identification of all the detailed activities that need to be carried out to get the application working, and provide information and instructions to all parties involved in implementation. The developers are required to make modifications to their application to allow it to run on the 23F Games Engine. The developer may need to liase with technical support to run test scripts on their applications prior to launch. If the tests are successful, the technical support team provide developers with access to the $23 \mathrm{~F}$ Games Engine and provide SMS shortcodes and assist with integrations to the SMS centre if required.

Stage 4 Launch and Monitor

The applications are launched after all of the following tasks are successfully completed: the application is working on live 23F Games Engine; live SMS shortcode routes calls to the appropriate application; the game has been integrated into website; live testing is successful and the confidentiality agreement and 
contract have been signed. The webmaster will monitor usage and feedback, after a pre-defined period the products will be judged against pre-defined criteria and a decision will be made to either recommend the product to the $\mathrm{MMO}_{2}$ channels or withdraw the application. If the decision to withdraw is made, the webmaster will instruct all necessary parties to bring about the withdrawal of the application. The application will be removed from the games engine and access to the systems will be withdrawn from the developer. The website will be updated and all contracts cancelled. If the product is recommended by the webmaster a demonstration is provided to the appropriate $\mathrm{MMO}_{2}$ channels to brand the product and incorporate into their portfolio.

Mobile applications are reviewed depending on the target market, consumer applications such as games are reviewed against suitability for the $23 \mathrm{~F}$ site and are processed using the four stages defined above, but it is not an obvious task to identify the components required for other types of applications. This view is confirmed by comments from the samurai "The categories used to register the products are too broad and don't really help to decide what components are required for each type of application prior to the development stage. A reference model is required which can provide an early view of the systems constituents ".

\section{Interpreting Mobile Internet applications with the Wireless Reference Model}

The Wireless Reference Model (WRM) described below is an empirically induced set of dimensions that can apply to any wireless computing project. The model was required to enable the various stakeholders to understand the different system components, and to provide a common vocabulary of terms for talking about these components. The various stakeholders collaborating with MADIC have a mixture of skills and backgrounds. Hence it was necessary for the model to allow for a consistent discussion of the prospective product's attributes, features, and structure in a way that characterises the view of the system as seen by the user and the view of the user as seen by the system. The dimensions of this reference model depicted in Figure IV include the following: Application layer, Program layer, Network layer and Device layer. 


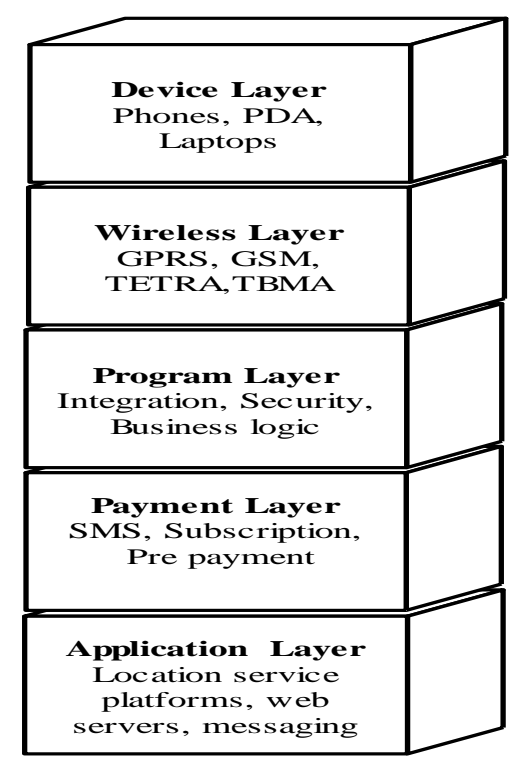

Figure IV :Wireless computing Reference Model

\section{Device Layer:}

The device layer is the first layer of the reference model. This layer is within the user domain and all interactions are conducted through this interface. The subscribers from the case study access the Internet using General Packet Radio Service (GPRS) via a mobile phone, Personal Digital Assistant (PDA) or laptop. A PDA can be integrated with a GPRS or GSM card. This layer deals with the issues such as the user interface, navigation and device software. Technologies that support development for mobile devices are J2ME, this is a version of Java language designed for small devices. Another example is Mobile Station Application Execution Environment (MExE), this is aimed at incorporating Java into mobile phones and providing full application programming. It is compatible with WAP but incorporates other features including voice recognition and positioning technology. Another technology aimed at mobile devices is PDA Web Clipping and PDA Syncing (Stemmer, Yasskin et al. 2002). PDA Web clipping allows popular PDA devices, such as Palms and Handsprings to access dynamic and updates HTML content via a modem.

\section{Network Layer:}

The second layer of the reference model is the transmission backbone involved in communications including transportation, transmission and switching for voice and data. The potential of ubiquitous data capable 
networks and the discovery of the wireless Internet are fuelling the demand for innovative data applications and services. The networks listed in Table V, have the bandwidth to support wireless data applications and provide wireless Internet access.

\begin{tabular}{|l|l|l|}
\hline Networks & Speed & Uses \\
\hline 2nd generation GSM & $\begin{array}{l}9.6 \text { kilobits per } \\
\text { second (KBPS) } \\
\text { SMS } 160 \mathrm{chr}\end{array}$ & Text Messaging FAX \\
\hline $\begin{array}{l}\text { High Speed Circuit Switched Data } \\
\text { (HSCSD) }\end{array}$ & $\begin{array}{l}\text { Between 28.8 } \\
\text { KBPS and 43.2 } \\
\text { KBPS. }\end{array}$ & $\begin{array}{l}\text { Internet, e-mail, calendar and file transfer } \\
\text { services }\end{array}$ \\
\hline General Packet Radio Service (GPRS) & $\begin{array}{l}171.2 \text { kilobits per } \\
\text { second (KBPS) }\end{array}$ & $\begin{array}{l}\text { Colour Internet, multimedia messages } \\
\text { and location-based services. }\end{array}$ \\
\hline EDGE & $\begin{array}{l}384 \text { KBPS } \\
\text { Downloading video and music multimedia } \\
\text { messaging, high-speed }\end{array}$ \\
\hline UMTS & $\begin{array}{l}\text { 144 KBPS - 2 } \\
\text { MBPS depending } \\
\text { on mobility }\end{array}$ & $\begin{array}{l}\text { Video on demand, high speed Internet, } \\
\text { data transfer }\end{array}$ \\
\hline
\end{tabular}

Table V :Data Capable wireless network

\section{Program Layer:}

This layer deals with security related issues, business logic, systems logic, data management issues and integration of the devices from the applications. The development of security standards is currently being addressed by WAP 2.0 protocols. In WAP 1.2, security is currently dealt with using the Wireless Transport Layer Security (WTLS), which encrypts data using Secure Sockets Layer (SSL) technology. Future developments of WAP (WAP-Forum) will introduce a WML Script Cryptolibrary and wireless Public Key Infrastructure (PKI). This will ensure integrity, privacy, authenticity and non-repudiation. The enterprise applications running on mobile devices connected over wireless a network are not fundamentally different from stationary ones, they must integrate to participate in complex business processes, reconcile data and receive event notifications. There are a number of products and languages to support application integration in a more structured way, reducing the need to link applications by "spontaneous" means, such as point-topoint connections using, screen scrapers, file transfers or manual retyping of data (Pezzini 2001). These new products are collectively known as integration middleware, and include integration brokers, Business Process Managers (BPMs) and integration servers. 


\section{Payment Layer:}

This layer describes the payment model to be applied for the service or use of the application. The method for collecting the payment from the subscriber should be explicitly stated by all parties to allow the revenue share model to be agreed. In the past there have been numerous intricate schemes for enabling mobile currency and payments e.g. Mobile Transaction and Mobile Commerce Information. The main problem with these pilots was that they all had specific handset or Subscriber Identity Module (SIM) requirements that are extremely restrictive in an era when upgrading handsets is anticipated once a year. In the case study none of the intelligent approaches described above was used. The four payment models implemented at MADIC are described below:

a) Mobile terminating Short Message Service (SMS): The subscriber pays for the service by receipt of an SMS message which may or may not contain the requested information. This is the most widely applied model used;

b) Subscription: The mobile user subscribes to a service and the network operator via the standard billing process deducts the payments;

c) Premium Short code: A short code is created for a specific service that is charged at an agreed amount per minute;

d) Pre-Payment Model: The subscriber tops up an account and is charged for accessing the service or downloading items such as movies, music or ring tones from the platform.

\section{Application Layer:}

In today's environment of wireless application development projects, most of a system's components are acquired ready to be installed via systems configuration. Some of the applications that reside in this layer include mobile information platforms, location based services platforms, games platforms and Messaging Platforms. The majority of the products registered with MADIC fit within this layer. 
The reference model's main use was to identify the resources required for a particular type of project. It was also used at the project initiation stage to describe the proposition from a business and technical perspective to the committee that made decisions on which application to progress. The reference model was originally created as a four-layer model by reviewing 15 projects under development and identifying a taxonomy of the various attributes. The model was then tested against 30 potential projects and the payment layer was added due to the complexities of identifying how and where the revenues share process would be processed.

\subsection{CONCLUSIONS}

MADIC was created as a 'Creative Innovation Centre' for third party developers to advance their ideas and concepts for $\mathrm{MMO}_{2}$ 's wireless data networks. This study revealed an interesting perspective on how mobile applications needed to be integrated and revealed the broad categories of mobile applications that existed in the marketplace aimed at the various sectors. Prior to the case study, it had ben a preconceived notion that there were few applications suitable for the Mobile Internet but this does not seem to be the case. What seems to be the problem is the complications involved with integrating the various applications. These complications do not just refer to the technical elements but issues such as service level agreements between the various parties, revenue sharing models, systems development approachers, maintainance contracts. The reference model provided a means to understand the complexity and incorporate the various elements involved in a wireless application.

\section{REFERENCES}

Anderson, N. (January 2002). "NTT DoCoMo i-Mode (portals)." Wireless Internet Report - Ovum.

Barnes, S. J. (2002). "The mobile commerce value chain: analysis and future developments." International Journal of Information Management 22(2): 91-108.

Docomoco (2003). "Home Website." http://www.nttdocomo.com/home.html. 
Gann, D. M. and A. J. Salter (2000). "Innovation in project-based, service-enhanced firms: the construction of complex products and systems." Research Policy 292000 955-972 29: 955-972.

Hughes, T. P. (1998). Rescuing Prometheus. New York.

Kindberg, T. and J. Barton (2001). "A Web-based nomadic computing system." Computer Networks-the International Journal of Computer and Telecommunications Networking 35(4): 443-456.

Lee, W. C. (1999). Summary of panel discussion: Future of mobile computing - Convergence of research and applications. Advances in Database Technologies. Berlin, Springer-Verlag Berlin. 1552: 380-381.

MacKenzie, M. (April 2000). WAP Market Strategies - OVUM Report.

Miles, R., C. Snow, et al. (1997). "Organizing in the knowledge age: anticipating the cellular form." Academy of Management Executive 11, 7-24. 11: 7-24.

Oftel (2003). "Mobile Publication." http://www.oftel.gov.uk/publications/market_info/2003/mobile/q3mobile0403.pdf.

Oftel (2003). "Research Publication." http://www.oftel.gov.uk/publications/research/2002/trenr0602.htm.

Olla, P. and N. Patel (2002). The Trend of Mobile Information Systems: Developing new IS Concepts to Support the new paradigm. UK Association of Information Systems 'The Trend of Mobile Information Systems: Developing new IS Concepts to Support the new paradigm., Leeds Metropolitan University UK.

Olla, P. and N. V. Patel (2002). "A Value Chain Model for Mobile Data Service Providers." Telecommunications Policy 26(9-10): $551-571$

Pezzini, M. (2001). "Mobile Applications Look for Hooks in the Enterprise." Gartner Report.

Rycroft, R. W. and D. E. Kash (1999). The Complexity Challenge:

Technological Innovation for the 21st Century. New York.

Spreitzer, M. and M. Theimer (1993). "Scalable, Secure, Mobile computing with Location Information." Communications of the ACM $36(7)$.

Stemmer, A., N. Yasskin, et al. (2002). "CROSS-PLATFORM ACCESS STRATEGIES: Integrate Mobile Applications with PC-Based Web." Jupiter Vision Report Cross- Platform Access Strategies GER00- V01 Jupiter Communications : jup.com.

WAP-Forum "(www.wapforum.org)." 